\title{
Characterization of a Virus that Causes Transient Aplastic Crisis
}

\author{
Neal S. Young, Philip P. Mortimer, Jeffrey G. Moore, \\ and R. Keith Humphries \\ Cell Biology Section, Clinical Hematology Branch, National \\ Heart, Lung, and Blood Institute, National Institutes of Health, \\ Bethesda, Maryland 20205; Virus Reference Laboratory, Central \\ Public Health Laboratory, London, NW 9 5HT, United Kingdom
}

bstract. Transient aplastic crisis in children with congenital hemolytic anemias has been linked epidemiologically to infection with a serum parvovirus-like virus (SPLV). The virus is found in the blood in the early stages of the crisis, and serum containing SPLV inhibits erythroid colony formation in vitro. After sedimentation of virus-containing sera through a sucrose density gradient, colony inhibitory activity is present in the particulate fraction and separate from serum immunoglobulins. No inhibitory activity can be recovered from convalescentphase sera after similar fractionation procedures. Inhibition of erythroid colony formation in vitro is not a feature of sera from other viral infections. The pattern of resistance of SPLV activity to chemicals and enzymes is compatible with it being a parvovirus. By using replating techniques, a target of SPLV has been identified as a late erythroid progenitor cell. Neither SPLV antigen nor antiSPLV IgM was present in the sera of patients with other forms of bone marrow failure.

\section{Introduction}

Children with sickle cell disease and other congenital hemolytic anemias sometimes develop temporary erythropoietic failure or aplastic crisis (1-3). Aplastic crises follow seemingly nonspecific viral illnesses, and in some populations, may occur in seasonal epidemics (4). Recent epidemiological studies have linked aplastic crises to infection with a specific viral agent, here termed serum parvovirus-like virus (SPLV) $(4,5,6)$. During the acute phase of the illness of some patients, an antigen identified with SPLV has been detected and the virus seen by electron mi-

Received for publication 5 May 1983 and in revised form 20 September 1983.

1. Abbreviations used in this paper: $\mathrm{BFU}$, erythroid burst colony-forming unit; CFU, erythroid colony-forming unit; FCS, fetal calf serum; IMDM, Iscove's modification of Dulbecco's medium; RIA, radioimmunoassay; SPLV, serum parvovirus-like virus.

The Journal of Clinical Investigation, Inc.

Volume 73 , January 1984, 224-230 croscopy. More frequently, an IgM class antibody to the virus has been detected by the time that the crisis is clinically evident and the first blood sample is taken (7). In a previous study (8), we have shown that serum containing SPLV inhibits hematopoietic colony formation in methylcellulose, with the strongest effect on the late erythroid progenitor, the CFU-E. The inhibitory effect of serum containing SPLV may be neutralized by serum containing antibody to the virus. Inhibitory effects were not dependent on complement nor affected by the presence of antihuman immunoglobulin, making it unlikely that the inhibition was mediated by immunological mechanisms. Fresh serum containing SPLV, which was obtained from a patient with an aplastic crisis associated with hereditary spherocytosis, was very potent, showing inhibition of erythroid colony formation by a $10^{-4}$ dilution of serum.

We now have further evidence that the inhibitory effect of serum from patients with transient aplastic crisis is due to infection of a hematopoietic progenitor cell with SPLV. We have investigated the physicochemical characteristics of this agent; the studies were necessarily preliminary given the limited amounts of virus-containing material currently available. Acutephase sera from other viral diseases have been screened for inhibitory activity in hematopoietic colony culture. In vitro experiments in which colony forming cells are physically isolated have identified the late erythroid progenitor, rather than an accessory cell required for hematopoiesis, as the target of SPLV. A relationship between SPLV infection and other forms of marrow aplasia has been sought.

\section{Methods}

Hematopoietic colony culture. Bone marrow cells were obtained from normal volunteers following informed consent and the approval of the National Heart, Lung, and Blood Institute Institutional Review Board. Posterior iliac crest bone marrow was aspirated directly into 1 $\mathrm{ml}$ Iscove's modification of Dulbecco's medium (IMDM) (Gibco Laboratories, Grand Island, NY) and $0.5 \mathrm{ml}$ preservative-free heparin (O'Neil, Jones, and Feldman, St. Louis, MO) containing $500 \mathrm{U}$. Mononuclear cells were separated by Percoll (Pharmacia Fine Chemical, Piscataway, $\mathrm{NJ}$ ) sedimentation according to the manufacturer's directions followed by two washes in IMDM-2\% fetal calf serum (FCS). Following incubation with virus-containing sera or other serum samples, bone marrow cells were plated at a concentration of $1 \times 10^{5} / \mathrm{ml}$ in IMDM containing $0.8 \%$ 
methylcellulose; $30 \%$ FCS; $1 \%$ bovine serum albumin; $2.5 \mu \mathrm{m} / \mathrm{ml}$ erythropoietin (Connaught, Willowdale, Ontario); and 10\% phytohemagglutinin-stimulated leukocyte condition media (9). Colonies were identified by their characteristic morphology, and enumerated on day 8 (CFUE), day 10 (CFU-C), and days 12 and 18 (mature and primitive BFUE (10).

Replating of erythroid bursts. For replating experiments, colonies derived from primitive erythroid burst-forming progenitors were selected early in their development (day 7 of incubation) before evidence of hemoglobinization. Such colonies can be readily identified as containing 100-200 large refractile cells arranged in an irregular pattern (11). By picking these colonies, a pure population of erythroid progenitors at the stage of CFU-E or later is obtained. Four to five bursts were picked by using a sterile tapered Pasteur pipette, pooled, and resuspended in 50 $\mu \mathrm{l}$ of IMDM-2\% FCS. Half of this cell suspension was then incubated with SPLV-containing sera and the other half incubated with control sera. Methylcellulose culture medium as described above was added to each aliquot and plated. CFU-E-derived colonies, which were the progeny of these bursts, were then enumerated after a further $8 \mathrm{~d}$ of incubation.

Assays and source of serum parvovirus-like virus and antibody to $S P L V$. For the experiments described here, several sources of SPLVcontaining serum were utilized. Serum J.B. was obtained early in the course of an aplastic crisis of a child with sickle cell disease, and it was positive for SPLV antigen by radioimmunoassay (RIA) but did not contain antibody, using standard methods, to SPLV. Immunoprecipitation and electron microscopy, performed as described (12) showed particles (Fig. 1) with the diameter and morphology associated with SPLV (13). In tests for CFU-E inhibition, this serum preparation was of similar potency to a previously reported SPLV-containing serum,

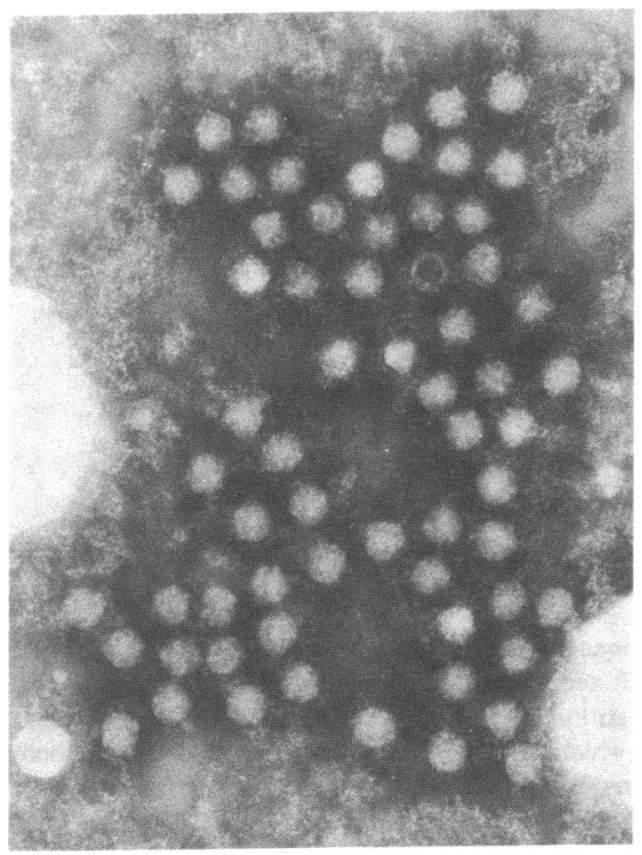

Figure 1. Parvovirus-like particles from human serum which were agglutinated by adding antibody and then were negatively stained with $3 \%$ phosphotungstic acid, $\mathrm{pH} 6.4(\times 165,000$; electron micrograph courtesy of Dr. A. M. Field).
J.H. (8), and inhibition of erythroid colony formation was detected up to a $10^{-4}$ dilution of serum (Fig. 2). Sera $\mathrm{Br} \mathrm{I}$ and $\mathrm{Br} \mathrm{II}$, from two of the original blood donors in whom SPLV antigen had been detected, were known to inhibit erythroid colony formation (8).

Serum from the convalescent phase of J.B.'s transient aplastic crisis was not available. Serum obtained at presentation of his sister, C.B., during recovery from an aplastic crisis, contained IgM antibody to SPLV. Similarly, a second convalescent-phase serum, S.H., that also contained specific IgM antibody, was obtained from the sibling of patient J.H. (14).

SPLV antigen was detected by RIA. Polystyrene beads were coated with anti-human $\mu$-chain antibody and then with human IgM with strong anti-SPLV activity. The bead was reacted with the test specimen. With washing steps between, a reagent derived from a mouse anti-SPLVsecreting monoclonal hybridoma and ${ }^{125}$ I-labeled anti-mouse Ig (kindly given by Dr. Harry Greenberg) were applied. After final washing, the bound radioactivity was measured in a gamma counter. Antibody to SPLV was detected by using counter immunoelectrophoresis (14) and RIA. To measure anti-SPLV-specific IgG and IgM, polystyrene beads were coated with anti-human $\mu$ - or $\gamma$-chain, reacted with the test specimen, and then with known SPLV antigen, anti-SPLV monoclonal reagent, and ${ }^{125} \mathrm{I}$-anti-mouse $\mathrm{Fc}$ as described above.

To assess inhibition of hematopoietic colony formation by SPLV, $150 \mu \mathrm{l}$ of a $10^{-2}$ dilution in IMDM of serum-containing SPLV or other serum samples were incubated with $3 \times 10^{5}$ mononuclear bone marrow cells at $37^{\circ} \mathrm{C}$ for $2-4 \mathrm{~h}$. After incubation, cells and virus were mixed with tissue culture medium and plated as described under colony culture. To test for stability of SPLV activity, $1.5 \mu \mathrm{l}$ of serum containing SPLV was diluted 1:10 in sterile solutions of enzyme or chemical and incubated overnight at $4^{\circ} \mathrm{C}$. Before addition of cells and methylcellulose culture medium, the sera were further diluted 1:10 in IMDM, to a final dilution of $10^{-2}$. Controls included normal sera treated in the same fashion to test for inhibition by the reagents. Enzymes tested included pancreatic

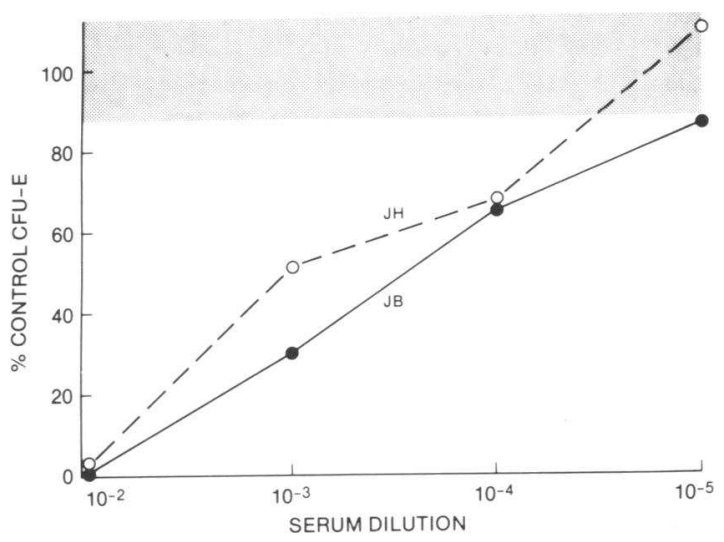

Figure 2. Titration of inhibition of erythropoiesis by two SPLVcontaining sera. Sera were obtained during the acute phase of aplastic crises in two individuals with hereditary spherocytosis (13), diluted in IMDM before addition of normal bone marrow cells, and incubated $4 \mathrm{~h}$ at $4^{\circ} \mathrm{C}$. Tissue culture medium was added and erythroid colonies counted on day 8 . The mean of colony number in three dishes is shown. The number of CFU-E-derived colonies in control dishes was $133 \pm 7 / 10^{5}$ nucleated cells. The range of control values obtained with similarly diluted normal sera is indicated by the shaded area. 
ribonuclease (Calbiochem-Behring Corp., San Diego, CA), micrococcal nuclease (Millipore, Bedford, MA), and pancreatic protease (Sigma Chemical Co., St. Louis, MO). Chemicals included potassium iodide, potassium thiocyanate, sodium deoxycholate (Sigma Chemical Co.), glycine- $\mathrm{HCl}$ (BRL, Bethesda, MD), ether (Mallinckrodt, Inc., St. Louis, MO), and chloroform (Fisher Scientific Co., Pittsburgh, PA).

To test for the presence of inhibitory levels of interferon, $135 \mu \mathrm{l}$ of serum containing SPLV, which was diluted $10^{-2}$, was incubated with $2.7 \mu$ goat immunoglobulin anti-human $\alpha$-interferon (kindly provided by Dr. J. Hooks, National Institutes of Health) for $\mathbf{3 0} \mathrm{min}$ at room temperature before addition to bone marrow cells as described above. Antibody added was sufficient to neutralize $\geq 100 \mathrm{U} \alpha$-interferon.

Sucrose density gradient fractionation. SPLV was separated from other serum components by sedimentation through a sucrose density gradient. $100 \mu \mathrm{l}$ of a 1 in 2 dilution of the serum under test were applied to a gradient comprised of layers of $40,30,20$, and $10 \%$ sucrose in phosphate-buffered saline, in a $4.5-\mathrm{ml}$ tube. The gradients were centrifuged for $16 \mathrm{~h}$ at $32,500 \mathrm{rpm}$ in a SW56 Beckman rotor (Beckman Instruments, Inc., Fullerton, CA) and 10-11 equal fractions of each collected from above. Fractions were tested for IgG and IgM content by double diffusion in agar against anti-human IgG and IgM sera; the precipitation lines being scored from $(+/-)$ (weak reaction) to $(+++)$ (very strong reaction). Selected fractions were examined for SPLV antigen by RIA.

\section{Results}

Separation of SPLV. Sera from six individuals were sedimented through sucrose density gradients (Fig. 3). SPLV-con-
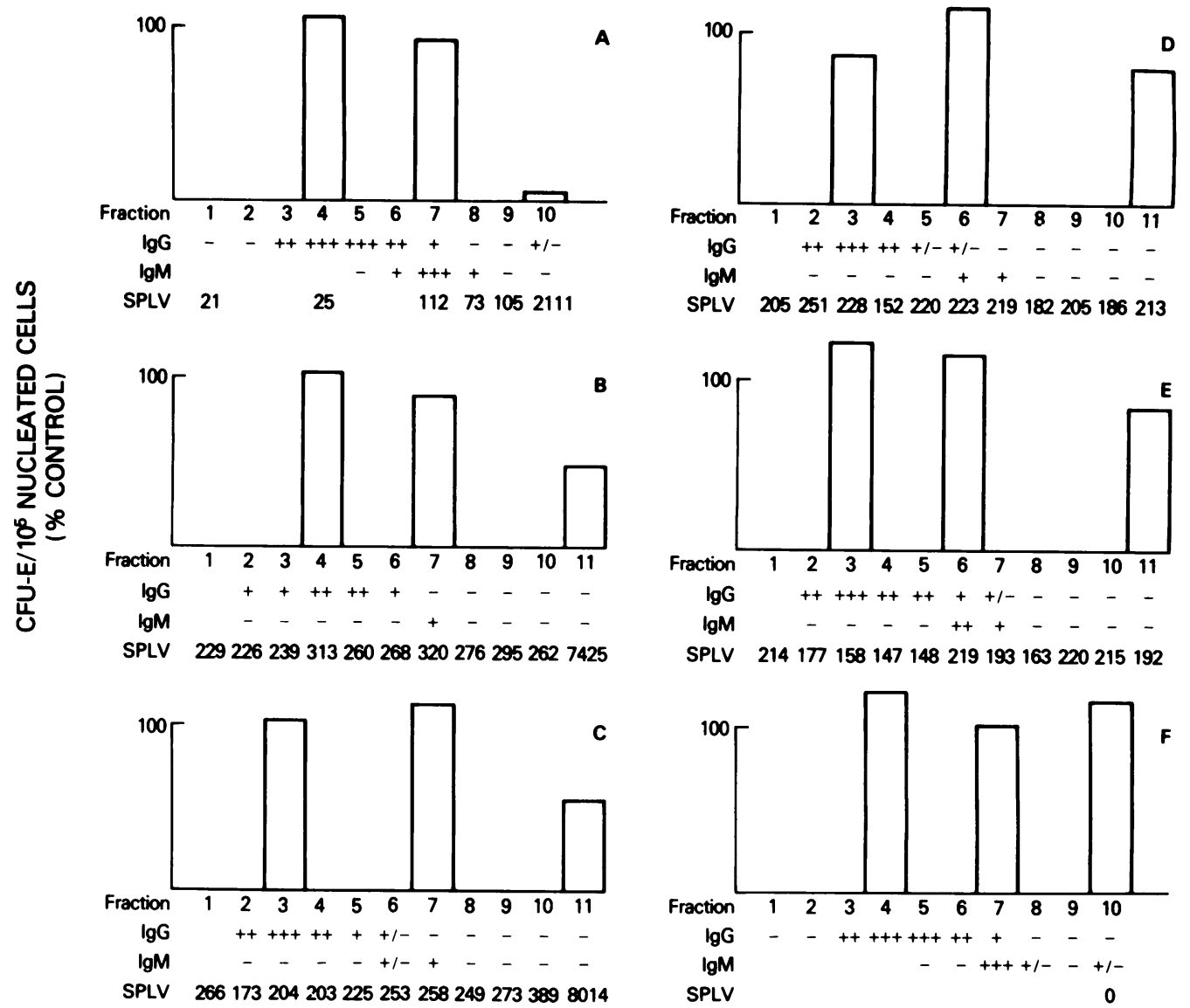

Figure 3. Fractionation of sera by sucrose density gradient sedimentation. Six sera were fractionated: $(A)$ J.B., a patient with sickle cell disease and transient aplastic crisis, whose sera contained SPLV antigen but not specific antibody; $(B)$ and $(C) \mathrm{Br} \mathrm{I}$ and $\mathrm{Br}$ II, respectively, sera from asymptomatic blood donors, which were also antigen-positive and lacked specific anti-SPLV antibody; $(D)$ and $(E)$ C.B. and S.H., respectively, from patients with hemolytic anemia during the convalescent phase of aplastic crisis, during which their sera contained anti-SPLV IgM antibody but not antigen; $(F)$ serum from a normal laboratory worker that lacked SPLV antigen and antibody. Sera $\mathrm{Br}$ I and $\mathrm{Br}$ II had been subjected to multiple freeze and thaw cycles; sera J.B., C.B., and S.H. had only been frozen and thawed once. Probably due to the relative heat susceptibility of SPLV activity, antigen titers have not been well-correlated with biological activity (8).

In these experiments, CFU-E-derived colonies in control dishes were $94 \pm 2 / 10^{5}$ mononuclear cells plated. CFU-E-derived colonies are represented in the bar graphs. IgG and IgM were determined by double diffusion in agar and the strength of the reaction indicated by $(+)$ signs. SPLV was measured by RIA and the results expressed as counts per 5 min. 10-11 fractions were collected from each gradient; fraction 1 was least dense, fraction 10-11 was densest. 
taining sera included patient J.B. and blood donors, $\mathrm{Br} \mathrm{I}$ and $\mathrm{Br}$ II, all of whose sera contained viral antigen but not antiSPLV antibody. Two sera from patients in the convalescent phase of transient aplastic crisis (S.H. and C.B.) contained antiSPLV IgM and no SPLV antigen. An individual whose serum contained neither SPLV nor antibody to SPLV served as a control. The method allowed separation of the IgG and IgM classes of immunoglobulins from virus particles as detected by RIA. Representative fractions, diluted $10^{-2}$ in IMDM to avoid inhibition by high concentrations of sucrose, were assayed for inhibition in the erythroid colony assay. Almost complete inhibition of erythroid colony formation was observed in the SPLV antigen-containing fraction from the individual with aplastic crisis whose serum was positive for antigen by RIA (Fig. $3 \mathrm{~A}$ ). Inhibition, but to a lesser degree, was observed in the densest fractions of sera $\mathrm{Br} \mathrm{I}$ and $\mathrm{Br}$ II (Fig. $3 B$ and $C$ ); these sera, from asymptomatic blood donors, had previously been repeatedly frozen and thawed. Inhibition was not present in immunoglobulin fractions, supporting an earlier observation that inhibition by SPLV-containing sera was not mediated by antibodies or complement. Inhibition was not observed in fractions of convalescent-phase sera (Fig. $3 D$ and $E$ ) or in normal serum (Fig. $3 \mathrm{~F}$ ).

Physicochemical features of SPLV. Physical and chemical features of the virus in serum J.B. were assayed by using the erythropoietic colony culture assay. As shown in Table $\mathrm{I}$, the virus was moderately sensitive to heat, but the pattern of sensitivity did not suggest the presence of an associated adenovirus; human adenoviruses type 1, 2, and 4 are largely inactivated

Table I. Physicochemical Features of SPLV

\begin{tabular}{lc}
\hline & $\%$ inhibition by J.B., \\
Treatment of SPLV-containing serum & $10^{-2}$ dilution \\
\hline $56^{\circ} \mathrm{C} \times 5 \mathrm{~min}$ & 0 \\
$48^{\circ} \mathrm{C} \times 30 \mathrm{~min}$ & 89 \\
$45^{\circ} \mathrm{C} \times 30 \mathrm{~min}$ & 99 \\
& \\
Ether & 100 \\
Chloroform & 100 \\
Sodium deoxycholate $.25 \%$ & 100 \\
RNase & 100 \\
Micrococcal DNase & 100 \\
Proteinase, $1 \mathrm{mg} / \mathrm{ml}$ & 0 \\
$\mathrm{KI}, 2.5 \mathrm{M}, \mathrm{pH} 7$ & $100^{*}$ \\
Glycine-HCl, pH 2.8 & 26 \\
HCl, $0.5 \mathrm{~N}$ & 28 \\
$\mathrm{NaOH}, 0.05 \mathrm{~N}$ & 4 \\
$\mathrm{No}$ treatment & 100 \\
&
\end{tabular}

* Performed on a $10^{-3}$ dilution of J.B. to avoid cytotoxic effect of KI. $10^{-2}$ dilutions of SPLV-containing serum were exposed to heat for the indicated time periods or to the enzymes and chemicals overnight at $4^{\circ} \mathrm{C}$ before addition of cells and methylcellulose culture medium. Controls included normal sera treated in the same manner.
Table II. Effect of Acute-phase Sera on Erythroid Colony Formation

\begin{tabular}{lcc}
\hline & $n$ & $\%$ control CFU-E \\
\hline Cytomegalovirus & 1 & 76 \\
ECHO virus type II & 1 & 102 \\
Epstein-Barr virus & 1 & 93 \\
Hepatitis A virus & 3 & $100 \pm 0$ \\
Hepatitis B virus & 5 & $90 \pm 20$ \\
Hepatitis virus, non-A, non-B & 5 & $78 \pm 12$ \\
Herpes simplex virus type 2 & 1 & 96 \\
Varicella-zoster virus & 1 & 60 \\
\hline
\end{tabular}

$n$, number of different sera tested.

after $10 \mathrm{~min}$ at $50^{\circ} \mathrm{C}(15)$ whereas SPLV was resistant to heating at $48^{\circ} \mathrm{C}$ for $30 \mathrm{~min}$. Virus activity was resistant to ether and chloroform, which is consistent with the absence of a lipid envelope. The pattern of resistance to a variety of enzyme treatments, acids, and bases were all compatible with a virus character. However, definitive identification must await determination of its proteins and its genetic material.

Effects on hematopoietic colony formation of acute-phase sera. Other components of serum present in the acute phase of viral infections might account for the colony inhibition produced by SPLV-containing sera, such as interferon (16) or endotoxin (17). To test this, acute-phase sera were obtained from patients with a variety of viral illnesses (Table II). These sera came from cases with typical clinical and serological features of the respective infections, and presumably contained those serum components associated with acute viral infection. None of the sera affected erythroid colony formation. Quantities of SPLV-containing sera were insufficient for direct measurements of interferon levels. However, incubation of such sera with goat anti-human interferon immunoglobulin sufficient to neutralize $100 \mathrm{U} \alpha$-interferon did not decrease inhibitory effects (data not shown). Thus, it appeared unlikely that the effects observed with SPLV-containing sera were due to nonspecific, acute-phase factors.

Target cell of SPLV. Because SPLV affects CFU-E and BFU-E and does not have a major effect on CFU-C, it was reasonable to postulate that the target cell is an erythroid hematopoietic progenitor (8). However, experiments done with total bone marrow cell suspension do not exclude the possibility of infection of a helper cell, such as T lymphocyte or macrophage, required for erythroid differentiation. This was a special concern because animal parvoviruses are known to infect lymphocytes (18) and monocytes $(19,20)$. An experiment was devised that could directly test the target cell for SPLV. Mature erythroid colonies derived from BFU-E in vitro are composed of thousands of normoblasts. If immature colonies, morphologically identifiable as derived from a burst-forming progenitor, are removed from primary tissue culture and suspended in new tissue culture media, multiple secondary colonies, which are similar in ap- 
pearance to colonies derived from CFU-E, are detected after replating. These secondary colonies arise from the population of late erythroid progenitors present in the immature burst, and at the time of plucking, grow in the absence of added helper or other bone marrow cells. As shown in Table III, exposure of such cells to SPLV-containing serum, either J.B. or Br II, before secondary plating decreased CFU-E colony formation in proportion to the inhibitory effects of partially purified virus. Serial observation by light microscopy showed that cells exposed to virus failed to multiply and lost their refractile appearance. These results are strong evidence that SPLV directly affects late erythroid progenitor cells and not an accessory cell required for erythroid differentiation.

SPLV and adult aplastic anemia. The relationship of SPLV infection to a variety of other bone marrow failure syndromes was investigated by testing for the presence of SPLV antigen and antibody to SPLV in the sera collected from patients with these disorders (Table IV). As the first viral agent that has been identified as specifically toxic to human bone marrow cells in culture, SPLV is a potential etiologic agent in bone marrow disorders. However, free viral antigen was not detected in patients with adult aplastic anemia, pure red cell aplasia, or transient erythroblastopenia of childhood. In addition, in the series of

Table III. Secondary Erythroid Colony Formation after Exposure to SPLV

\begin{tabular}{ccc}
\hline & \multicolumn{2}{l}{ CFU-E/10 mononuclear } \\
\cline { 2 - 3 } & cells & SPLV \\
\hline & Control & \\
Experiment 1 (J.B.) & & 4 \\
Group 1 & 42 & 0 \\
2 & 86 & 0 \\
3 & 140 & 2 \\
4 & 104 & \\
Experiment 2(Br II) & & 0 \\
Group 1 & 11 & 38 \\
2 & 54 & 21 \\
3 & 34 & 33 \\
4 & 114 & 144 \\
Control & 116 & 156 \\
& 140 & \\
\hline
\end{tabular}

Early-appearing bursts were individually removed from cultures and pooled in groups of five; half of each pool was exposed for $2 \mathrm{~h}$ to control serum and the other half exposed to SPLV-containing serum. Cells were then suspended in methylcellulose culture media and replated. CFUE-derived colonies were counted $8 \mathrm{~d}$ later. Equal division of pooled bursts was confirmed by measurement of split samples in the absence of SPLV (control/control). Serum J.B. was obtained from a child with aplastic crisis and assayed prior to freezing; serum $\mathrm{Br}$ II, from one of the original asymptomatic blood donors, had been repeatedly frozen and thawed.
Table IV. Assay of SPLV Antigen and Anti-SPLV Antibody in Bone Marrow Failure Syndromes

\begin{tabular}{|c|c|c|c|c|}
\hline & $n$ & $\begin{array}{l}\mathrm{Ag}^{+} / \text {total } \\
\text { tested }\end{array}$ & IgM $^{+} /$total & $\operatorname{Ig} G^{+} /$tota \\
\hline Adult aplastic anemia & 37 & $0 / 11$ & $3 / 28^{*}$ & $23 / 36$ \\
\hline Congenital aplastic anemia & 2 & $0 / 2$ & $0 / 2$ & $0 / 2$ \\
\hline Pure erythrocyte aplasia & 6 & $0 / 5$ & $1 / 5^{*}$ & $4 / 6$ \\
\hline $\begin{array}{l}\text { Transient erythroblastopenia } \\
\text { of childhood }\end{array}$ & 21 & $0 / 21$ & $0 / 21$ & $7 / 21$ \\
\hline $\begin{array}{l}\text { Paroxysmal nocturnal } \\
\text { hemoglobinuria }\end{array}$ & 3 & $0 / 3$ & $0 / 3$ & $1 / 3$ \\
\hline
\end{tabular}

$n$, total number of patients' sera available for assay.

* IgM reactive at low levels and probably not specific.

Antigen and antibody assays were performed as described in Methods. In some cases, if tests for anti-SPLV IgG were negative, anti-SPLV IgM was not assayed.

One serum sample from a patient with amegakaryocytic thrombocytopenia as found to be anti-SPLV IgG negative.

patients with adult aplastic anemia, the incidence of viral antibody was not higher than that reported in a normal European population. It is thus improbable that these diseases are, like transient aplastic crises of congenital hemolytic anemias, the expression of an acute infection with SPLV. However, the possibility that a proportion of adult bone marrow failures are due to delayed effects of SPLV infection has not been excluded.

\section{Discussion}

In an earlier publication (8), we reported that SPLV-containing sera inhibits the formation of erythroid colonies in vitro, and this is consistent with epidemiologic evidence that links SPLV infection to the aplastic crisis of sickle cell disease. However, many factors inhibit cell growth in culture, including cells, antibodies, endotoxin, lymphokines, and chemical ions. Therefore, we have taken care to identify and characterize the inhibitor present in SPLV-containing sera as well as its target in the bone marrow. Inhibition by SPLV-containing sera is not complement dependent nor blocked by anti-human immunoglobulin antibody, and thus it is unlikely to be immunologically mediated. In fact, the inhibitory effect on erythropoiesis can be localized to the densest, virus-containing fraction from a sucrose density gradient and is physically separable from immunoglobulin in serum. Inhibition by SPLV-containing serum is unaffected by ribonuclease and deoxyribonuclease, but abolished by protease, which is consistent with a virus effect. Resistance to ether and chloroform indicates that the virus is not lipid-enveloped. Sensitivity of the inhibitory effect to $\mathrm{pH}$ extremes is consistent with the physical properties of other parvoviruses $(20,21)$; in contrast, the similar sized picornaviruses are generally $\mathrm{pH}$ labile (22). However, viral activity is sensitive to heating at $56^{\circ} \mathrm{C}$ for $5 \mathrm{~min}$, which is not typical of most well-characterized parvoviruses. However, the immunosuppressive variant of minute virus of 
mouse is much more thermolabile than the nonlymphotropic strain (18).

The failure of a variety of sera obtained during other acute viral illnesses to inhibit erythropoiesis under the same experimental conditions indicates that endotoxin or some other nonspecific component of infected serum is not responsible for the observed biologic effect. This finding also suggests that toxicity for erythropoietic cells is not necessarily a common feature of viral infection, even those that like Epstein-Barr virus (22) or non-A non-B hepatitis virus (23) have been associated clinically with bone marrow failure.

The profound effect of SPLV or secondary colony formation by isolated erythroid bursts identified an erythroid progenitor as a target cell for the virus. The more pronounced effect, in vitro, of SPLV-containing sera on CFU-E compared with BFU$E$ may be a particular feature of the interaction of virus and its host cell, and possibly be related to the maturation of virusbinding sites like glycophorin (24) on developing erythroid cells. The increased sensitivity of CFU-E in comparison with BFU$E$ also may be related to the higher proportion of CFU-E that are actively proliferating (25). Parvoviruses, the smallest DNAcontaining viruses, have a genome consisting of only 5,000 base pairs of nucleotide (26), and parvovirus replication in the nucleus, therefore, is highly dependent on constituents provided by the cell during mitosis (27). The difficulty of maintaining erythroid progenitors in suspension culture may also account for our inability to obtain functional virus from short-term suspension bone marrow cultures (unpublished observations).

The highly proliferative erythroid bone marrows of patients with chronic hemolytic diseases may be an especially good environment for parvovirus replication. Certainly, SPLV infection of these individuals interrupts hematopoiesis and causes sudden worsening of anemia. It is tempting to speculate that infection with SPLV or a related virus has led to outbreaks of temporary erythroid hypoplasia among hospitalized patients undergoing treatment for kwashiorkor (28) and that SPLV is responsible for hematodepressive virus disease described in Thailand (29). Whether hematopoiesis is perturbed in otherwise healthy people infected with SPLV is a moot point as anemia has not been documented in these patients.

SPLV antigen was not detected in the sera of patients with other forms of bone marrow failure, nor was the prevalence of antibody to SPLV increased in patients with adult aplastic anemia. These diseases cannot, therefore, follow the same pattern of acute SPLV infection associated with rapid development of aplasia that occurs in transient aplastic crises. However, acute SPLV infection and destruction of a stem cell earlier in the hematopoietic lineage than the CFU-E might not become clinically apparent until weeks or even months after the clearance of viral antigen from the blood, and this may be a mechanism leading to some forms of aplastic anemia. Chronic persistent or latent infection with a virus, such as SPLV, are other mechanisms by which infection might lead to bone marrow failure without the features of the acute disease seen in children with aplastic crisis.
SPLV is the first human virus identified as cytotoxic to human hematopoietic cells. Identification of this virus and its target cell represent steps towards the goal of growing the virus in vitro. Immunization of children with congenital hemolytic anemias would be a feasible project and would lead to the elimination of aplastic crises as a complication of their diseases. The study of the interaction of SPLV and hematopoietic cells also serves as a model for other virus-host relationships that may lead to bone marrow failure.

\section{Acknowledgments}

The authors gratefully acknowledge the contribution of sera by Dr. Naomi Luban and Dr. John Kelleher, Washington Children's Hospital Medical Center; Dr. Sanford Krantz, Vanderbilt University Medical Center; Dr. Blanche Alter, Mt. Sinai Medical Center; and Dr. Steven Strauss, National Institute of Allergy and Infectious Diseases. Dr. Bernard Cohen, Central Public Health Laboratory, and Dr. Robert Purcell, National Institute of Allergy and Infectious Diseases, provided generous assistance and advice.

\section{References}

1. Gasser, C. 1957. Aplasia of erythropoiesis. Pediatr. Clin. N. Am. 445-468.

2. Van Der Sar, A. 1967. Aplastic sickle cell crisis. Trop. Geogr. Med. 19:273-285.

3. Pardoll, D. M., R. J. Rodeheffer, R. R. L. Smith, and S. Charache. 1982. Aplastic crisis due to extensive bone marrow necrosis in sickle cell disease. Arch. Intern. Med. 142:2223-2225.

4. Serjeant, G. R., K. Mason, J. M. Topley, and B. E. Serjeant. 1981. Outbreak of aplastic crises in sickle cell anaemia associated with parvovirus-like agent. Lancet. II:595-597.

5. Pattison, J. R., S. E. Jones, J. Hodgson, L. R. Davis, J. M. White, C. E. Stroud, and L. Murtaza. 1981. Parvovirus infections and hypoplastic crisis in sickle-cell anaemia. Lancet. I:664-665.

6. Anderson, M. J. 1982. The emerging story of a human parvoviruslike agent. J. Hyg. (Camb.). 89:1-8.

7. Anderson, M. J., L. R. Davis, S. E. Jones, and J. R. Pattison. 1982. The development and use of an antibody capture radioimmunoassay for specific IgM to a human parvovirus-like agent. J. Hyg. (Camb.). 83:309-324.

8. Mortimer, P. P., R. K. Humphries, J. G. Moore, R. H. Purcell, and N. S. Young. 1983. A human parvovirus-like virus inhibits hematopoietic colony formation in vitro. Nature (Lond.). 302:426-429.

9. Aye, M. T., Y. Niho, J. E. Till, and E. A. McCulloch. 1974. Studies of leukemic cell populations in culture. Blood. 44:205-219.

10. Gregory, C. J., and A. C. Eaves. 1977. Human marrow cells capable of differentiation in vitro. Definition of three erythroid colony responses. Blood. 49:855-864.

11. Cashman, J., D. Henkelman, R. K. Humphries, C. Eaves, and A. Eaves. 1983. Individual BFU-E in polycythemia vera produce both erythropoietin dependent and independent colonies. Blood. 61:876.

12. Cohen, B. J., P. P. Mortimer, and M. S. Pereira. 1983. Diagnostic assays with monoclonal antibodies for the human serum parvoviruslike virus (SPLV). J. Hyg. 91:113-130.

13. Cossart, Y. E., A. M. Field, B. Cant, and D. Widdows. 1975. Parvovirus-like particles in human sera. Lancet. I:72-73. 
14. Kelleher, J., N. L. C. Luban, P. P. Mortimer, and T. Kamimura. 1983. Human serum "parvovirus": a specific cause of aplastic crisis in children with hereditary spherocytosis. J. Pediatr. 102:720.

15. Gineberg, H. S. 1956. Characteristics of the new respiratory viruses (adenoviruses). II. Stability to temperature and $\mathrm{pH}$ alterations. Proc. Soc. Exp. Biol. Med. 93:48-58.

16. Ortega, J. A., A. Ma, N. A. Shore, P. P. Dukes, and T. C. Merigan. 1979. Suppressive effect of interferon on erythroid cell proliferation. Exp. Hematol. (Lawrence.). 7:145-149.

17. Quesenberry, P., J. Levin, K. Zuckerman, N. Rencricca, R. Sullivan, and W. Tyler. 1979. Stem cell migration induced by erythropoietin or haemolytic anemia: the effects of actinomycin and endotoxin contamination of erythropoietin preparations. Brit. J. Haematol. 41:253269.

18. Engers, H. D., J. A. Louis, R. H. Zubler, and B. Hirt. 1981. Inhibition of T cell-mediated functions by MVM(i). A parvovirus closely related to minute virus of mice. J. Immunol. 127:2280-2285.

19. Paul, P. S., W. L. Mengeling, and T. T. Brown, Jr. 1979. Replication of porcine parvovirus in peripheral blood lymphocytes, monocytes, and peritoneal macrophages. Infect. Immun. 25:1003-1007.

20. Porter, D. D., and H. J. Cho. 1980. Aleutian disease of mink: a model for persistent infection. Virus-host interactions: vivid invasion, persistence, and disease. In Comprehensive Virology. H. Fraenkel-Conrat and R. Wagner, editors. Plenum Press, New York. 16:233-256.

21. Siegl, C. 1976. The Parvoviruses. Springer-Verlag New York, Inc., New York. 109.

22. Fenner, F., B. R. McAuslan, C. A. Mims, J. Sambrook, and
D. O. White. 1974. The Biology of Animal Viruses. Academic Press, Inc., New York. 102.

23. Shadduck, R. K., A. Winkelstein, Z. Zeigler, J. Lichter, M. Goldstein, M. Michaels, and B. Rabin. 1979. Aplastic anemia following infectious mononucleosis: possible immune etiology. Exp. Hematol. (Lawrence.). 7:264-271.

24. Hagler, L., R. A. Pastore, and J. J. Bergin. 1975. Aplastic anemia following viral hepatitis: report of two fatal cases and literature review. Medicine. (Baltimore). 54:139-164.

25. Bukrinskaya, A. G. 1982. Penetration of viral genetic material into host cell. Adv. Virus Res. 27:141-204.

26. Eaves, C. J., R. K. Humphries, and A. C. Eaves. 1978. In vitro characterization of erythroid precursor cells and the erythropoietic differentiation process. In Cellular and Molecular Regulation of Hemoglobin Switching. G. Stamatoyannopoulos and A. W. Nienhuis, editors. Grune \& Stratton, Inc., New York. 251-278.

27. Tattersall, P., and D. Ward. 1978. The Parvoviruses-An Introduction in Replication of Mammalian Parvoviruses. D. Ward and P. Tattersall, editors. Cold Spring Harbor Laboratory, Cold Spring Harbor, New York. 3-12.

28. Rose, J. A. 1974. Parvovirus reproduction. In Comprehensive Virology. H. Fraenkel-Conrat and R. Wagner, editors. Plenum Press, New York. 3:1-61.

29. Walt, F., J. E. D. Taylor, F. B. Magill, and A. Nestadt. 1962. Erythroid hypoplasia in kwashiorkor. Brit. Med. J. I:73-75.

30. Bierman, H. R., and E. R. Nelson. 1965. Hematodepressive virus diseases of Thailand. Ann. Intern. Med. 62:867-884. 